\title{
3 Research Square \\ Evaluation of standardized training effect for surgery residents based on WeChat public platform
}

\section{Jianchun Xiao}

Peking Union Medical College Hospital Department of General Surgery

\section{Ruilin Zhou}

Peking Union Medical College Hospital

Chen Lin

Peking Union Medical College Hospital Department of General Surgery

Jiaolin Zhou

Peking Union Medical College Hospital Department of General Surgery

\section{Xin Ye}

peking union medical college hospital

Bin Wu ( $\nabla$ pumc2000@163.com )

https://orcid.org/0000-0002-5318-1736

\section{Research article}

Keywords: WeChat public platform, standardized training, surgery residents

Posted Date: May 27th, 2020

DOI: https://doi.org/10.21203/rs.3.rs-29671/v1

License: (c) (1) This work is licensed under a Creative Commons Attribution 4.0 International License.

Read Full License 


\section{Abstract \\ Background}

Recent years, with the wide application of WeChat, new teaching methods have been established. Current teaching reforms are mainly based on the usage of WeChat's group chat function. We intend to establish our teaching reform based on WeChat platform function instead of the traditional group chat function. To explore the feasibility and teaching effect of a new teaching model based on WeChat public platform in standardized training and teaching of surgical residents, we designed this study.

\section{Methods}

Residents who underwent standardized training of residents in Peking Union Medical College Hospital from January 2019 to December 2019 were assisted by using "PUMCH surgical standardized training", which is a teaching product based on WeChat platform. "PUMCH surgical standardized training" WeChat public platform comprise regular lectures, trainings, classroom notes, extra-curricular reading and many other learning materials, which can all be easily downloaded from WeChat platform, providing a new teaching method for medical students. After one year of training, teaching evaluation was conducted through objective structured clinical examinations. Compare objective structured clinical examination results with previous years.

\section{Results}

Residents who received WeChat public platform teaching had higher clinical operation and clinical speculative scores than residents who received traditional teaching. There were no other teaching reforms taken place during this year, and the difficulty of the tests were the same. To eliminate the impact of clinical experience on test scores, we selected two different groups of students in our training. The results of the questionnaire showed that residents thought WeChat public platform assisted teaching was superior to traditional teaching.

\section{Conclusion}

The teaching interaction of WeChat public platform is helpful to improve the teaching effect of surgical resident physician training, and the application effect is satisfactory.

\section{Background}

Resident standardized training (hereinafter referred to as "regulation") refers to graduates of medical majors and above who have completed basic school education and received systematic and standardized training mainly to improve their clinical practice ability at a certified training base [1]. In 
recent years, educators at various medical institutions of higher learning have continuously explored the application of WeChat in medical teaching, involving internal medicine, surgery, obstetrics and gynecology, pediatrics, neurology, nursing and many other disciplines.[2-5] Teaching content includes physical examination and surgical operations, case discussion, medical record writing, etc. However, these reforms are mainly based on WeChat's group chat, circle of friends and other functions. There is less exploration on the application of WeChat public platform to medical education, especially the standardized training of surgical residents. Since 2018, our surgical department has begun to explore the application of WeChat public platform in the teaching of surgical resident, and design and implement the difficult points in the current surgical teaching in order to improve the quality of teaching. The purpose of this study is to explore the effectiveness of WeChat public platform-assisted teaching in surgical training. The results are reported below.

\section{Methods}

\section{Research object}

A total of 70 residents who were trained in our hospital from January 2019 to December 2019 were selected, and they were taught in the traditional mode instead of the WeChat teaching mode as the traditional teaching group. From January 2019 to December 2019, WeChat public platform teaching was added to the teaching based on traditional teaching and a total of 112 residents in our hospital were selected to serve as the WeChat platform teaching group.

\section{Research Methods}

Teaching methods: (1) Combining with listening-based teaching methods: Based on WeChat platform, "PUMCH surgical standardized training" provide a rich online-database resource, which includes diagnosis and treatment guide for each department, diagnosis and treatment routine, operation video, regular lectures, trainings in various departments, and other important lectures in the hospital. After refining and summarizing classroom teaching content, WeChat public platform released courseware, classroom recording or video, classroom notes, and extra-curricular reading for students to read online or download at any time. One advantage of WeChat public platform is that the study can take place at any time and any place, which can create more convenience for students. (2) Combination with problembased teaching methods: Based on WeChat platform, "PUMCH surgical standardized training" raises clinical problems in articles, and students can discuss solutions in the comment area and write down their answers, and finally the teacher analyzes the questions and reviews the students' answers; (3) combined with the case-based teaching method: "PUMCH surgical standardized training" WeChat platform has set up a case sharing column, soliciting and publishing interesting and difficult cases, teachers In the tweet, the points of the case that are worthy of discussion and inquiry are pointed out. The students can type their opinions in the comment area, and the teacher guides the discussion. In the next tweet of the column, the teacher will arrange and comment on the students' answers. (4) Combination 
with online assessment: "PUMCH surgical standardized training" WeChat platform not only has the above methods for teaching, but also provide evaluation methods to assess the learning effect of medical students. Teachers can publish online-test on "PUMCH surgical standardized training" WeChat platform and students are allowed to finish the test in a certain period of time. The online test on "PUMCH surgical standardized training" WeChat platform has various forms, including multiple choice, short answer questions, case discussions. Teachers can either set up the test questions by their selves or extract questions from the question bank, and the later can adjust test difficulty from easy to hard.

Evaluation method Relevant approvals have been obtained at the time of teaching reform(1)Objective assessment. We adopted the Objective Structured Clinical Examination (OSCE), which includes theoretical tests and surgical assessments, and the full score is 850 points, to assess the learning results using WeChat platform. The test results of the WeChat platform teaching group and the traditional teaching group are compared. The two groups shows significant difference. (2) Subjective assessment. A questionnaire (see supplement) was issued to 112 residents in the experimental group (a total of 138 questionnaires were issued, and 112 were actually recovered, all of which are valid). The questionnaire included several questions on different aspects of the new teaching method based on WeChat public platform. The 112 students are demanded to evaluate their selves in scores from 1 to 10 ( 1 stands for "no help at all" and 10 stands for "very helpful").

Statistical methods SPSS 19.0 software was used for statistical analysis. Compare the OSCE test results (hereinafter referred to as the test group) with previous OSCE results (hereinafter referred to as the control group) by t-test. $\mathrm{P}<0.05$ is considered statistically significant.

\section{Results}

\section{OSCE test scores of two groups}

Comparing the total OSCE scores, theoretical scores, and operational test scores of the Wechat platform teaching group with the traditional model teaching group, it was found that the total OSCE scores of the students using the WeChat platform teaching group ( $698.4 \pm 49.9$ vs. $666.5 \pm 42.5, p<0.001)$ Is significantly higher than the traditional model teaching group, the theoretical results of the WeChat platform teaching group $(72.2 \pm 12.8$ vs. $77.7 \pm 9.8, p<0.001)$ and the operation test $(87.2 \pm 5.5$ vs. $94.5 \pm$ $3.0, p<0.001)$ are also high In the traditional mode teaching group.

\section{Questionnaire Results}

The results of the questionnaire are shown in Table 1. The survey shows that the average number of times students open public platforms is $3-5$ times per week $(72.7 \%)$, and the average learning time per opening is mainly below 10 minutes (45\%) and more than 10 minutes $(41 \%)$. According to the survey of usage, the teaching platform helps to promote regular students to improve their learning initiative, 
strengthen the grasp of clinical knowledge, and help cultivate clinical thinking. There is no advantage in literature reading ability, clinical operation level and interpersonal communication and writing.

Table 1

Analysis and evaluation of education effect

\begin{tabular}{|ll|}
\hline Investigation items & Average Score \\
\hline Mastery of knowledge & $3.8 \pm 0.5$ \\
\hline Improve learning initiative & $3.6 \pm 0.3$ \\
\hline Literature reading ability & $1.8 \pm 0.7$ \\
\hline Clinical Thinking Training & $4.2 \pm 0.2$ \\
\hline Clinical operation level & $1.5 \pm 0.5$ \\
\hline Interpersonal communication and collaboration & $1.5 \pm 0.3$ \\
\hline
\end{tabular}

\section{Discussion}

\section{Overview of WeChat platform}

WeChat is a free application that provides instant messaging services for mobile smart terminals. It was launched by Tencent on January 21, 2011. On this basis, Tencent launched the WeChat public platform. Through streaming media sharing, enterprises, groups and individuals can push graphics, voice, video and other content to achieve real-time communication with users. The popularity of WeChat, as well as the immediacy, privacy, and variety of its content, make it a huge educational potential. In recent years, educators at various medical institutions of higher learning have continuously explored the application of WeChat in medical teaching, involving internal medicine, surgery, obstetrics and gynecology, pediatrics, neurology, nursing and many other subjects, case discussion, medical record writing, etc. [6]. However, these reforms are mainly based on WeChat's group chat, circle of friends and other functions. There is less exploration on the application of WeChat public platform to medical education, especially the standardized training of surgical residents. This article uses the public account of "PUMC training in teaching" as an example to explore the application of WeChat public platform in surgical training.

The "PUMC standardized surgical trainingWeChat public account is a subscription number created by the Peking Union Medical College Hospital Surgery. It was created in December 2017. It has published nearly a hundred medical-related articles and nearly 1,000 subscribers, covering all the students in our hospital, and radiated to the surgical training outside the hospital. Each quarter, the teaching team and the public accountant of the Peking Union Medical College Hospital determine the teaching theme, and publish solicitations for the teaching staff of this hospital and outside hospitals. The returned manuscripts are reviewed by the teaching team and published by the public account management team. After reading and learning in Pearson, our college forwarded it in the circle of friends or WeChat group to complete the study and check-in and promotion. 


\section{WeChat platform's importance in surgical teaching}

Surgery is a special discipline in medicine, which integrates theoretical knowledge, clinical operation, interpersonal communication, and teamwork. Its complexity and comprehensiveness place high demands on surgery teaching and also bring greater challenges - - the traditional education model is gradually unable to meet the teaching needs of surgery, and educators must constantly seek new and more applicable education models and teaching platforms. The popularity of WeChat, as well as the immediacy, privacy, and variety of its content, make it a huge educational potential. According to the feedback results of the questionnaire (see supplement), it can be seen that most doctors in training support the application of the teaching platform, and the teaching response is good. We believe that the WeChat public platform has the following advantages for the training of surgical residents.

\section{The advantages of WeChat Platform over teaching platforms in western countries.}

In western countries, they also provide many learning platforms for clinical students. Although the learning platforms in western countries cover most functions that WeChat platform provides, there are absolute advantages of WeChat platform over western countries' platforms[7-9]. First of all, WeChat platform is easy to spread. In China, the use of WeChat is ubiquitous. Every surgical resident use WeChat in his or her daily work and study to communicate with each other. Since people are familiar with WeChat, it's easier to accept WeChat platform. For example, the Kahoot ${ }^{\circledR}$ gamification program used in Finland must operate on a computer[9] and is unavailable on the phone. In comparison, the WeChat platform can operate on cellphone, which provides a lot more convenience for surgical residents to study during their spare time. Second, using WeChat platform don't have to download new applications in cell phone. Downloading new applications not only occupy a lot of space in cell phone, but also take time to get familiar with it. Third, unlike online courses in western countries, using WeChat platform can skip the cumbersome steps for creating new account. In western countries, students must create an account on the online teaching platforms to use websites and discussion boards [10]. However, the WeChat platform can skip this step since surgical residents already has a WeChat account of his or her own. Since the WeChat platform is relied on WeChat, the login information is defaulted as the WeChat account.

\section{The advantages of WeChat platform over traditional teaching mode}

\section{Diversity}

In surgical learning, we must not only master a wealth of theoretical knowledge, but also cultivate skilled clinical operations. Therefore, surgical teaching needs to have rich content and diverse teaching forms to meet the learning needs of students, which is difficult to achieve through traditional books and 
classrooms [11]. For example, the operation video is played in the classroom for auxiliary teaching, and the students sitting in the back row cannot concentrate because they cannot see the focus in the video. The time in the classroom is limited, and the teacher 's teaching must be biased, which leads to insufficient breadth and depth of knowledge acquired by the students in the classroom. In contrast, the variety of content and forms pushed by the WeChat public platform make its teaching potential even better. In terms of content, the "PUMC Regulation Teaching" covers a wide range of contents, ranging from common clinical skills and treatment methods to image reading and doctor experience sharing. Some contents that are commonly used in clinic and focus on attention will be repeated in a review form after a period of time. In terms of form, the WeChat public platform can push messages including graphics, pictures, voices, and texts to users, and video, audio, and animation can be inserted into the graphics messages. When watching videos on personal mobile devices, you can pause and replay at any time when you encounter unclear content, and you can undoubtedly gain more knowledge from the video. For example, after searching for "knotting", a total of 9 graphic messages related to knotting were published from 2017 to the present by "PUMC Specification Training", and 3 of them explained in detail the common methods of suture and knotting in surgery. With pictures and texts, accompanied by video explanations, so that medical students suddenly look bright. Therefore, the students in the experimental group learn through the WeChat public platform, and the clinical operation results are higher. Under this colorful teaching mode, students' learning interest is more intense, and learning autonomy is stronger.

\section{Efficiency}

Today's society is moving towards a "fragmented" model. The accelerating social rhythm brings fragmentation of time, and the rapid development of network technology brings fragmentation of information. Junior medical students can still use the complete time module in the classroom to concentrate on the basic knowledge and skills related to surgery, but in the surgical teaching of graduate students and senior doctors, the traditional, complete time module of collective classroom learning is not realistic. WeChat push is usually concise and refined, with a strong focus, and you can get a lot of valuable knowledge points in a short time of reading. Users can collect useful content that they wish to learn, and start learning or reviewing at any time during their free time. For example, we can use WeChat public platform to fully condense the clinical manifestations, auxiliary examinations, diagnosis and treatment of a disease in a short tweet, and medical students can follow up with it. "PUMC Regulation Teaching" is generally pushed from 8 to 9 in the evening, which happens to be a relatively relaxing time for medical workers, who can accept new knowledge in a relaxed and happy mood. Therefore, through the WeChat public platform, the fragmented knowledge is embedded in the fragmented time, making the knowledge transfer process more efficient.

\section{Interactivity}

Lack of interaction between teachers and students, students and students is one of the main problems of the LBL teaching model. The teaching models such as PBL, CBL or TBL, which were developed later, paid special attention to this problem, try to arouse the enthusiasm of students and increase the participation 
of students [12]. During the interaction with the students, teachers can timely understand the students' various doubts and thoughts, and provide supplementary explanation and expansion of knowledge in a more targeted manner. The interaction between students is helpful for thinking collision, experience sharing and mutual learning. WeChat public platform is a natural interactive platform. Subscribers can send messages in the background, and the public account administrator is responsible for sorting and replying to the messages. Both subscribed users and non-subscribed users can leave a message after the original push, and the message processed by the public account administrator ("selected") is visible to everyone. For example, the teaching platform will publish the imaging reading challenge. Users can send their own answers in the background of the public account, and the correct answers and users with correct answers will be announced in the next push. The message at the end of the tweet is an experience exchange platform for medical students and doctors. For example, "The four biggest fears of ICU on duty! Just ask you if you are afraid!" In the article, graduate students and resident doctors told their own experience in the message area, which is just a combination of the summary in the article and practical work practice. In the "case sharing" section, medical students directly shared interesting or difficult cases they encountered during the internship in the form of tweets, and shared their experiences with readers. The "Clinical Speculation" score in the OSCE test of the experimental group is higher, which is inseparable from the exchange of clinical experience.

\section{Immediacy}

As a science, it is especially important to keep up with the times. However, the speed of revision of textbooks often cannot keep up with the speed of updating the guidelines, and even less can keep pace with the advancement of basic theories, auxiliary examinations, and treatment methods. As a new media form of teaching, WeChat public platform is very instant. In the "Guide to Download" section, users can find the latest version of the relevant surgical diseases directly or through search. The diagnostic criteria, surgical indications, and treatment recommendations are clear at a glance. This study does not involve the assessment of the knowledge and application of medical frontier knowledge, and further research can be carried out in the future.

\section{Conclusion}

In conclusion, this study takes the training of surgical residents as an example, and made some reforms and explorations using the WeChat platform. The study shows that the platform can improve the quality of teaching, not only shown by the test scores but also approved by students' self-evaluation. Teaching by WeChat platform has the advantage of diversity teaching style, efficiency learning using scattered free time, interaction with teachers, and immediacy to keep up with new knowledge. Although this research is still in its infancy and needs more practice, but it shows significant effect in surgical teaching and may provide a potential new way of teaching medical students.

\section{Declarations}




\section{Ethics approval and consent to participate}

Our study does not involve clinical trial, it is just a reform of teaching methods. This new teaching method based on WeChat public platform is neither a denial nor a change of traditional teaching method. The new teaching method is an addition to the traditional teaching methods, so there is no harm to the interests of students. Our hospital 's ethics committee said our study is unnecessary to pass ethics.

\section{Consent for publication}

Not applicable.

\section{Availability of data and materials}

The datasets used and/or analyzed during the current study are available from the corresponding author on reasonable request.

\section{Competing interests}

The authors declare that they have no competing interests

\section{Funding}

The Graduate Education Teaching Reform Project of Peking Union Medical College Hospital, Chinese Academy of Medical Sciences, No. 10023201700102. This fund mainly provides financial support for the creation and maintenance of this platform and the payment of study materials including surgery videos, class-notes, lectures, etc. The operation of our platform is supported by this fund.

\section{Author's contribution}

JX designed the project, conducted the study, collected data, and contributed to writing the article. RZ conducted the literature search, analyzed and interpreted statistical data, and wrote the majority of the article. CL, JZ, XY contributed to revising the article. BW contributed to study design and oversaw the study. All authors read and approved the final manuscript.

\section{Acknowledgements}

The authors like to thank all surgery residents who participated in this study.

\section{References}

1. Hu G, Wang J, Wang Y. Residency status of implementation of standardized training system analysis. J Cardiovascular Pulmonary Dis. 2011;30(6):547-9.

2. Zhang W, Li ZR, Li Z. WeChat as a Platform for Problem-Based Learning in a Dental Practical Clerkship: Feasibility Study. J Med Internet Res. 2019;21:3. 
3. Wang F, Xiao LD, Wang K, Li M, Yang Y. Evaluation of a WeChat-based dementia-specific training program for nurses in primary care settings: A randomized controlled trial. Appl Nurs Res. 2017;38:51-9.

4. Wang J, Gao F, Li J, Zhang J, Li S, Xu G. et al. The usability of WeChat as a mobile and interactive medium in student-centered medical teaching. Biochem Mol Biol Educ. 2017;45(5):421-5.

5. Liu X, Cheng J, Huang S. Mobile Phone Training Platform for the Nursing Staff in the Emergency Department. Telemed J E Health. 2019;25(1):66-70.

6. Antepohl W, Herzig S. Problem-based learning versus lecture-based learning in a course of basic pharmacology: a controlled, randomized study. Med Educ. 1999;33(2):106-13.

7. Davis J, Chryssafidou E, Zamora J, Davies D, Khan K, Coomarasamy A. Computer-based teaching is as good as face to face lecture-based teaching of evidence based medicine: a randomised controlled trial. BMC Med Educ. 2007;7:23.

8. Roshier AL, Foster N, Jones MA. Veterinary students' usage and perception of video teaching resources. BMC Med Educ. 2011;11:1.

9. Felszeghy S, Pasonen-Seppänen S, Koskela A, Nieminen P, Härkönen K, Paldanius K. et al. Using online game-based platforms to improve student performance and engagement in histology teaching. BMC Med Educ. 2019;19(1):273.

10. Kühbeck F, Berberat PO, Engelhardt S, Sarikas A. Correlation of online assessment parameters with summative exam performance in undergraduate medical education of pharmacology: a prospective cohort study. BMC Med Educ. 2019;19(1):412.

11. Apramian T, Cristancho S, Watling C, Ott M, Lingard L. "They Have to Adapt to Learn": Surgeons' Perspectives on the Role of Procedural Variation in Surgical Education. J Surg Educ. 2016;73(2):339-47.

12. Blosser A, Jones B. Problem-based learning in a surgery clerkship. Med Teach. 1991;13(4):289-98.

\section{Supplementary Files}

This is a list of supplementary files associated with this preprint. Click to download.

- AttachmentQuestionnaire.docx 